\title{
Adult Intussusception: An Uncommon Condition and Challenging Management
}

\author{
Mohamed Tarchouli, ${ }^{\mathrm{a}, \mathrm{b}}$ Abdelmounaim Ait Ali ${ }^{\mathrm{c}, \mathrm{d}}$ \\ a Department of Surgery, First Medical and Surgical Center, Agadir, Morocco; b Faculty of Medicine and Pharmacy, \\ Sidi Mohamed Ben Abdellah University, Fez, Morocco; ' ${ }^{C}$ epartment of Visceral Surgery, Mohammed V Military \\ Hospital, Rabat, Morocco; ${ }^{\mathrm{d}}$ Faculty of Medicine and Pharmacy, Mohammed V University, Rabat, Morocco
}

\section{Keywords}

Intussusception · Adult · Diagnosis · Management · Surgery

\begin{abstract}
Introduction: Intussusception is a rare condition in adults. A pathological lesion is usually found with a significant percentage of malignancy. The optimal treatment is still not universally clear. Methods: This is a retrospective review of adult patients with a diagnosis of intestinal intussusception and surgically treated at our institution from January 2009 to December 2018. Clinical, operative, and histological details were collected and analyzed. Results: A total of 26 cases, 16 males and 10 females, were diagnosed with surgically proven intussusception during the 10-year period. The mean age was 45 years (range 21-70). Using ultrasound and/or computed tomography as imaging study, the preoperative diagnosis was made in $21 / 26$ (81\%) patients. Five intussusceptions were discovered only upon exploratory laparotomy for intestinal obstruction. There were 19 (73\%) cases of enteric and $7(27 \%)$ cases of colonic intussusceptions. All patients underwent surgical exploration. Intestinal resection with immediate anastomosis was the technique of choice for most patients. A single patient underwent stoma for peritonitis secondary to intestinal perforation. An organic cause has been systematically revealed, and no idiopathic intussusception was detected. Etiology was malignant in 9 (35\%) cases. Conclusion: Adult intussusception should be considered in any patient with subacute abdominal pain. Considering the
\end{abstract}

high rate of malignancy, intestinal resection without attempting reduction is highly recommended for colonic intussusceptions. However, a more selective approach can be adopted for enteric intussusceptions.

(c) 2020 S. Karger AG, Basel

\section{Introduction}

Intussusception, first described by Paul Barbette in 1674 , is defined as the invagination of an intestinal segment (intussusceptum) into the lumen of another adjacent segment (intussuscipiens) $[1,2]$. It can lead to intestinal obstruction and exposes the patient to the risk of parietal ischemia, perforation, and peritonitis. Intussusception in adults is entirely different from the pediatric form, especially regarding clinical, pathological, and therapeutic aspects. Intussusception in children is a common disease, usually idiopathic without an identified lead point. Clinical presentation is often acute and easily recognized by the classic triad of abdominal pain, rectal bleeding, and a palpable abdominal mass. Most cases can be successfully treated by hydrostatic or pneumatic reduction without surgical intervention. In contrast, intussusception in adults is a rare disorder that represents only $1 \%$ of intestinal obstructions and nearly $5 \%$ of all intussusception cases [3-5]. Unfortunately, clinical signs are often nonspecific and make diagnosis difficult. Nevertheless, the widespread use of computed tomography (CT) for abdominal complaints has significant- 


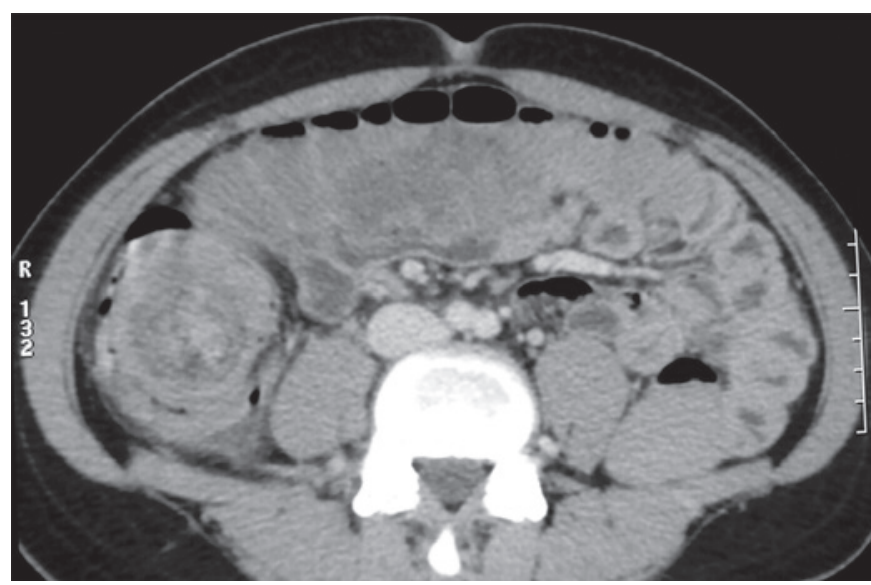

Fig. 1. Ileo-colic intussusception due to cecum adenocarcinoma in a 30-year-old woman. Axial contrast-enhanced CT scan showing a typical round target-shaped mass with bowel wall thickening.

Table 1. Symptoms of patients with intussusception

\begin{tabular}{ll}
\hline Symptoms & $n / N(\%)$ \\
\hline Abdominal pain & $24 / 26(92)$ \\
Nausea/vomiting & $22 / 26(85)$ \\
Abdominal distension & $10 / 26(38)$ \\
Constipation & $9 / 26(35)$ \\
Palpable abdominal mass & $7 / 26(27)$ \\
Diarrhea & $6 / 26(23)$ \\
Weight loss & $5 / 26(19)$ \\
Anorexia & $3 / 26(12)$ \\
Rectal bleeding & $3 / 26(12)$ \\
Fever & $2 / 26(8)$ \\
\hline
\end{tabular}

ly increased the detection of adult intussusception, especially transient and asymptomatic forms. The typical bowel-within-bowel appearance often containing mesenteric fat and blood vessels is pathognomonic. Most adult intussusceptions are due to pathological lead point with approximately $60 \%$ of malignancy [6-8]. Usually, surgical exploration is needed to verify the diagnosis and exclude an underlying malignancy. However, there is no universal consensus about indications of intraoperative reduction and the extent of intestinal resection.

This study reports our experience and discusses clinical features, diagnosis, and optimal management of this uncommon entity.

\section{Materials and Methods}

A retrospective study was conducted over a period of 10 years. This study included all adult patients (aged 18 years or older) treated for intestinal intussusception at Mohammed V Military Hospital of Rabat, Morocco, from January 2009 to December 2018. Sur-

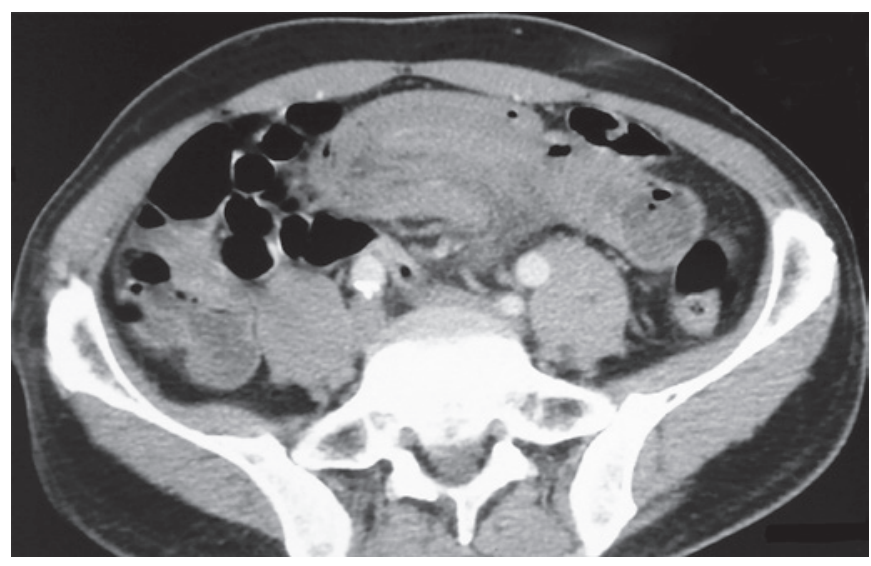

Fig. 2. Enteric intussusception due to fibrous polyp in a 58-yearold man. Contrast-enhanced CT scan shows a sausage-shaped mass with edematous bowel wall in the ileal loop. Mesenteric vessels and fat tissues are seen in the center of the mass.

gical data were from patients' medical records. Clinical presentation, investigation findings, operative details, and histological reports were collected and analyzed.

Patients were divided into 2 groups according to the lead point location: enteric intussusceptions and colonic intussusceptions. The enteric form is confined to the small bowel, including jejunojejunal, jejuno-ileal, and ileo-ileal intussusceptions. The colonic form includes colocolonic and colorectal intussusceptions. Ileocolic intussusception is considered as enteric if the lead point is ileal (proximal to the ileo-cecal valve) and as colonic if the lead point is colonic (distal to the ileo-cecal valve). Rectal prolapse was excluded from this classification. Anterograde intussusception was defined by telescoping of an intestinal segment into the lumen of another proximal segment. Inversely, retrograde intussusception corresponded to telescoping of an intestinal segment into the lumen of another distal segment. Acute symptoms were defined as symptoms that typically lasted $<4$ days, as subacute when lasting from 4 to 14 days, and as chronic when lasting $>14$ days.

Intussusception was preoperatively diagnosed by abdominal ultrasound and/or CT scan. All patients underwent surgical treatment using an open or laparoscopic approach, and the timing of surgery depended on the urgency of the patient's clinical presentation.

\section{Results}

\section{Age and Gender Data}

A total of 26 patients, 16 males and 10 females, were diagnosed with adult intussusception during the 10-year period. The mean age was 45 years, with a range of $21-70$ years. The male-to-female ratio was 1.6:1.

\section{Clinical Presentation}

Out of the 26 patients, $8(31 \%)$ were admitted to the emergency department with clinical signs of acute intestinal obstruction, and 1 of them had peritonitis. The other 18 (69\%) had subacute to chronic symptoms suggestive of subacute obstruction, such as episodic abdominal pain and nausea/vomiting. A palpable mass was found in $7 \mathrm{pa-}$ 
Fig. 3. Ileo-ileal intussusception due to adenomyoma in a 25 -year-old man. Contrast-enhanced CT scan showing the pathognomonic "target sign" on the sagittal view $(\mathbf{A})$ and the typical "sausage-shaped sign" on the frontal view (B).

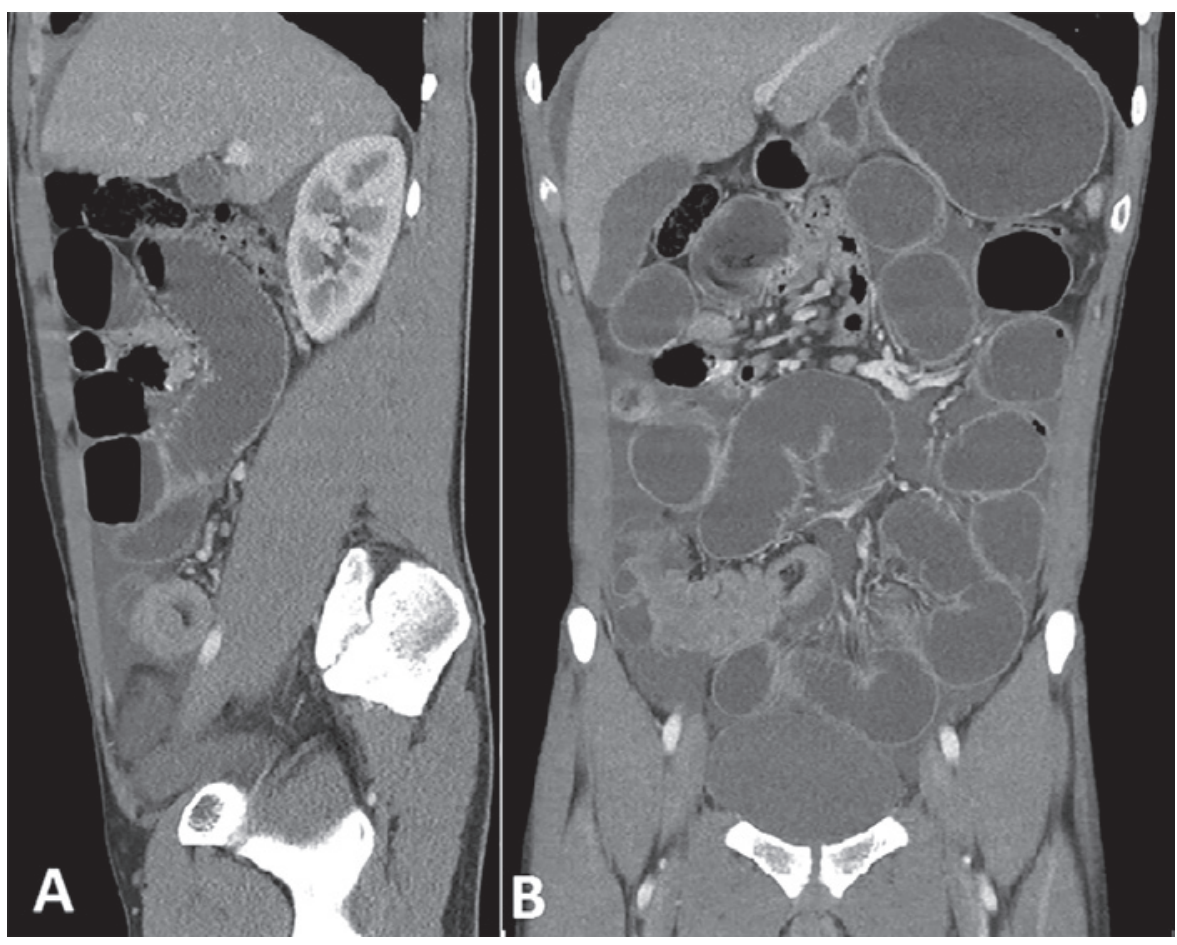

tients at abdominal examination, but none had the classic pediatric triad. The time from symptoms onset to diagnostic confirmation varied from 1 day to 2 years. Details of symptoms and clinical signs are listed in Table 1.

\section{Diagnostic Modalities}

Plain abdominal radiography, performed only in patients with acute clinical presentation, showed hydro-air levels typical of intestinal obstruction. Abdominal ultrasound was done in 17 patients, which revealed classical images (target sign or pseudokidney sign) highly suggestive of intestinal invagination in 9 of them (53\% accuracy). Abdominal CT scan, undertaken in 23 patients, confirmed intussusception in 21 patients (91\% accuracy; Fig. 1-3). However, a pathological lead point was found in only 10 patients out of the 21 (48\%). Total colonoscopy, performed in 3 patients, revealed intussusception secondary to cecum adenocarcinoma in 1 patient (Table 2). Moreover, 5 cases were discovered only upon exploratory laparotomy for intestinal obstruction. Overall, preoperative diagnosis of intussusception was made in 21/26 (81\%) patients using the above-mentioned modalities.

\section{Treatment and Postoperative Course}

All patients underwent surgical intervention. Eight of them (31\%) were admitted with acute intestinal obstruction and required emergency surgery. The other nonurgent patients $(n=18,69 \%)$ were operated on the basis of elective surgery. Open laparotomy was usually used as a surgical approach, whereas laparoscopic surgery was suc-
Table 2. Preoperative diagnostic studies

\begin{tabular}{lcc}
\hline Study & $\begin{array}{l}\text { Subjects, } \\
n(\%)\end{array}$ & $\begin{array}{l}\text { Accuracy, } \\
n(\%)\end{array}$ \\
\hline Abdominal radiography & $11(42)$ & $0(0)$ \\
Abdominal ultrasound & $17(65)$ & $9(53)$ \\
Abdominal CT scan & $23(88)$ & $21(91)$ \\
Colonoscopy & $3(11)$ & $1(33)$ \\
\hline
\end{tabular}

cessfully performed in 4 patients (Fig. 4, 5). Surgical procedures depended on the location of intussusception, the presumed cause, and the viability of intestinal segments.

Preoperative reduction was not adopted in our management of adult intussusceptions. In contrast, intraoperative reduction was generally attempted in all enteric intussusceptions except for 2 patients as malignancy was strongly suspected during surgical exploration. Reduction attempt also failed in 2 patients due to hard irreducible underlying masses. This reduction was intentionally avoided in colonic intussusceptions. However, it was successfully performed in the unique colorectal intussusception in order to reduce the extent of intestinal resection and to preserve the anal sphincter.

The most frequently performed procedure was segmental intestinal resection $(n=16,61 \%)$. The other procedures were right hemicolectomy $(n=6,23 \%)$, ileocecal resection $(n=2,8 \%)$, segmental sigmoidectomy $(n=1,4 \%)$, and proctosigmoidectomy $(n=1,4 \%)$. All resections were performed with primary anastomosis except for 1 patient who 

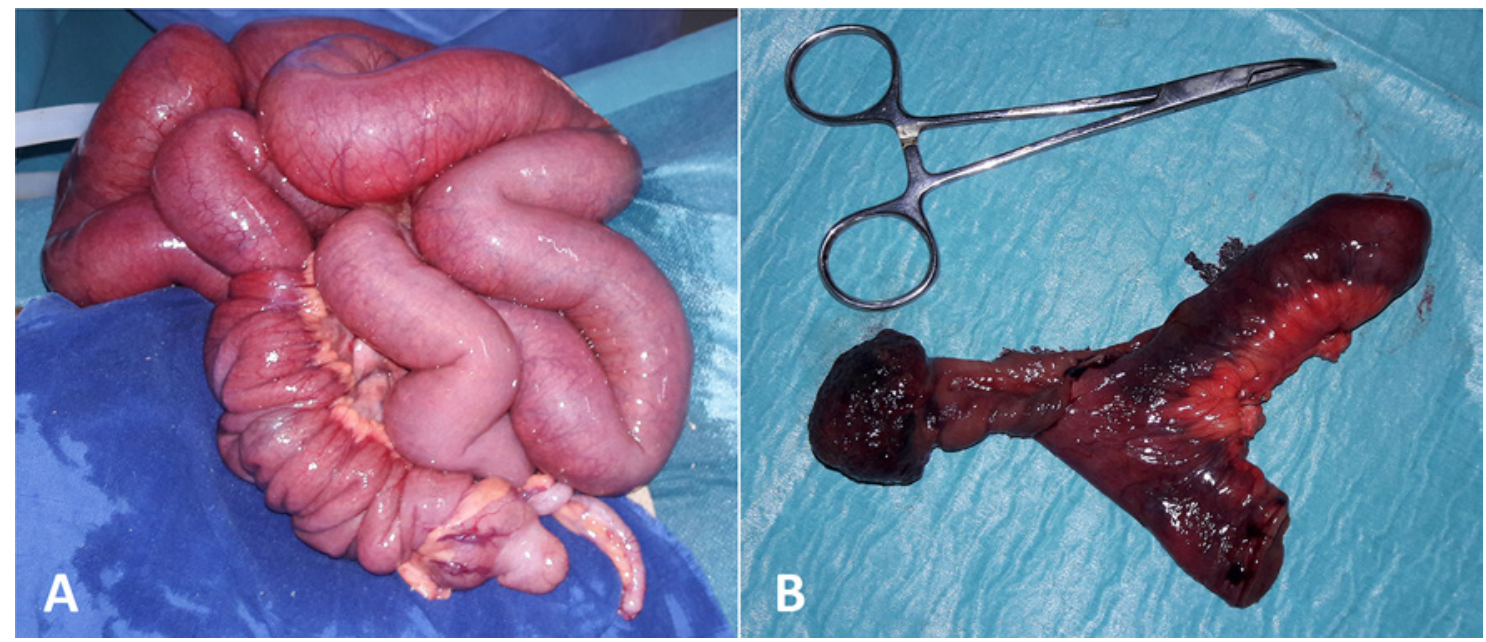

Fig. 4. Operative view (laparotomy) of an ileo-ileal intussusception (A) secondary to adenomyoma acting as a lead point (B).

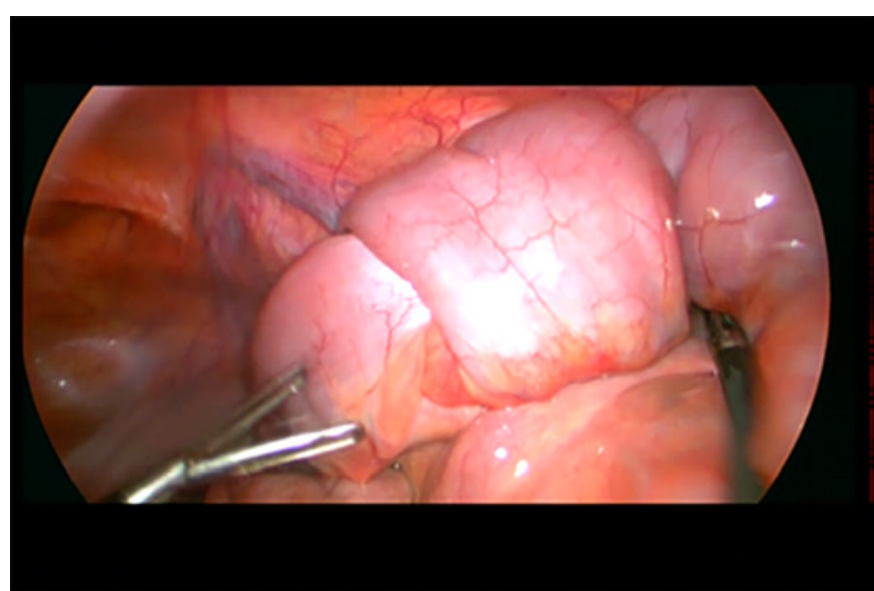

Fig. 5. Operative view (laparoscopy) of an ileo-ileal intussusception.

underwent a stoma for peritonitis caused by intestinal perforation. Details of location, type of intussusception, etiology, and operative procedures are shown in Table 3.

Postoperative complications were observed in $5 \mathrm{pa}-$ tients: 3 cases of surgical site infections, 1 of minor anastomotic leak, and 1 of pulmonary infection. They were successfully treated during the postoperative period.

\section{Location and Etiologies}

Surgical exploration confirmed intussusception in all patients and determined its type, location, and causative lesion. Enteric intussusceptions $(n=19,73 \%)$ were more predominant than colonic intussusceptions $(n=7,27 \%)$. One case of enteric intussusception was jejuno-jejunal, 3 were jejuno-ileal, 12 were ileo-ileal, and 3 were ileocolic. Five cases of colonic intussusception were ileocolic, 1 was colocolonic, and 1 patient had colorectal intussusception. No case of retrograde intussusception was observed in our series.
A pathological lead point was identified in all patients after examination of resected specimens. Benign pathologies were revealed in 17 cases (65\%) and malignant processes in 9 cases (35\%). The most common benign lesion leading to intussusception was fibrous polyp of Vanek ( 6 cases). The other benign lesions included lipoma, leiomyoma, adenomyoma, intestinal tuberculosis, Meckel's diverticulum, nonspecific inflammation, and postoperative adhesion. Out of the 9 malignant etiologies, primary adenocarcinoma was the most frequent (4 cases), and others included malignant lymphoma, leiomyosarcoma, gastrointestinal stromal tumor, and undifferentiated carcinoma. Overall, malignant lesions were encountered in $26 \%$ of enteric intussusceptions and $57 \%$ of colonic ones. Different etiologies are summarized in Table 4.

\section{Discussion}

Intussusception in adults is an unusual condition compared to its pediatric counterpart. It is found in only $0.08 \%$ of all abdominal surgery $[9,10]$. In our study, the mean age was lower than that reported in previous studies [11-13]. The gender prevalence is generally equal between males and females; however, a slight male predominance was recorded in our report $[14,15]$.

In contrast to the pediatric form, the clinical presentation of adult intussusception is mostly variable and nonspecific. Adult patients often present with intermittent or chronic symptoms indicating incomplete intestinal obstruction. The classic triad of abdominal pain, rectal bleeding, and abdominal palpable mass is rarely encountered $[16,17]$. Obviously, most of our patients presented with intermittent abdominal pain and nausea/vomiting, 
Table 3. Details of location, etiology, and operative procedures of adult intussusceptions

\begin{tabular}{|c|c|c|c|c|c|c|}
\hline Case & $\begin{array}{l}\text { Age, years/ } \\
\text { sex }\end{array}$ & Type & Surgery & Reduction & $\begin{array}{l}\text { Location } \\
\text { of lead point }\end{array}$ & Histopathology \\
\hline 1 & $39 / f$ & jejuno-jejunal & SI segmental resection & $\mathrm{Y}$ & jejunum & fibrous polyp \\
\hline 2 & $48 / \mathrm{m}$ & jejuno-ileal & SI segmental resection & $\mathrm{N}$ & jejunum & adenocarcinoma \\
\hline 3 & $26 / f$ & jejuno-ileal & SI segmental resection & $\mathrm{Y}$ & jejunum & leiomyosarcoma \\
\hline 4 & $70 / f$ & jejuno-ileal & SI segmental resection & $\mathrm{Y}$ & jejunum & lipoma \\
\hline 5 & $56 / f$ & ileo-ileal & SI segmental resection (L) & $\mathrm{Y}$ & ileum & leiomyoma \\
\hline 6 & $34 / \mathrm{m}$ & ileo-ileal & SI segmental resection & $\mathrm{Y}$ & ileum & Meckel's diverticulum \\
\hline 7 & $56 / \mathrm{m}$ & ileo-ileal & SI segmental resection & $\mathrm{Y}$ & ileum & $\begin{array}{l}\text { B-cell malignant } \\
\text { lymphoma }\end{array}$ \\
\hline 8 & $25 / \mathrm{m}$ & ileo-ileal & SI segmental resection & $\mathrm{F}$ & ileum & adenomyoma \\
\hline 9 & $58 / \mathrm{m}$ & ileo-ileal & SI segmental resection & $\mathrm{Y}$ & ileum & fibrous polyp \\
\hline 10 & $21 / \mathrm{m}$ & ileo-ileal & SI segmental resection (L) & $\mathrm{Y}$ & ileum & postoperative adhesion \\
\hline 11 & $55 / f$ & ileo-ileal & SI segmental resection & $\mathrm{Y}$ & ileum & fibrous polyp \\
\hline 12 & $70 / \mathrm{m}$ & ileo-ileal & SI segmental resection & $\mathrm{Y}$ & ileum & fibrous polyp \\
\hline 13 & $28 / \mathrm{m}$ & ileo-ileal & SI segmental resection (L) & $\mathrm{Y}$ & ileum & adenomyoma \\
\hline 14 & $70 / \mathrm{m}$ & ileo-ileal & SI segmental resection & $\mathrm{Y}$ & ileum & leiomyoma \\
\hline 15 & $46 / \mathrm{m}$ & ileo-ileal & SI segmental resection & $\mathrm{N}$ & ileum & GIST \\
\hline 16 & $51 / \mathrm{m}$ & ileo-ileal & SI segmental resection & $\mathrm{Y}$ & ileum & $\begin{array}{l}\text { undifferentiated } \\
\text { carcinoma }\end{array}$ \\
\hline 17 & $52 / f$ & ileocolic & right hemicolectomy & $\mathrm{F}$ & ileum & $\begin{array}{l}\text { nonspecific } \\
\text { inflammation }\end{array}$ \\
\hline 18 & $22 / \mathrm{m}$ & ileocolic & ileocecal resection & $\mathrm{Y}$ & ileum & fibrous polyp \\
\hline 19 & $31 / \mathrm{m}$ & ileocolic & ileocecal resection & $\mathrm{Y}$ & ileum & fibrous polyp \\
\hline 20 & $58 / f$ & ileocolic & right hemicolectomy & $\mathrm{N}$ & cecum & intestinal tuberculosis \\
\hline 21 & $47 / f$ & ileocolic & right hemicolectomy & $\mathrm{N}$ & cecum & adenocarcinoma \\
\hline 22 & $30 / f$ & ileocolic & right hemicolectomy $(\mathrm{L})$ & $\mathrm{N}$ & cecum & adenocarcinoma \\
\hline 23 & $32 / \mathrm{m}$ & ileocolic & right hemicolectomy & $\mathrm{N}$ & colon & Burkitt lymphoma \\
\hline 24 & $59 / \mathrm{f}$ & ileocolic & right hemicolectomy & $\mathrm{N}$ & colon & lipoma \\
\hline 25 & $42 / \mathrm{m}$ & colocolonic & sigmoidectomy & $\mathrm{N}$ & colon & lipoma \\
\hline 26 & $32 / \mathrm{m}$ & colorectal & proctosigmoidectomy & $\mathrm{Y}$ & sigmoid & adenocarcinoma \\
\hline
\end{tabular}

SI, small intestine; L, laparoscopic surgery; Y, successful reduction; N, reduction not attempted; F, reduction failed; GIST, gastrointestinal stromal tumor.

Table 4. Etiologies and location of adult intussusceptions

\begin{tabular}{lrrr}
\hline \multirow{2}{*}{ Etiologies } & \multicolumn{2}{l}{ Location } & \multirow{2}{*}{ Total } \\
\cline { 2 - 3 } & enteric & colonic & \\
\hline Benign & 14 & 3 & 17 \\
$\quad$ Fibrous polyp & 6 & 0 & 6 \\
Lipoma & 1 & 2 & 3 \\
Leiomyoma & 2 & 0 & 2 \\
Adenomyoma & 2 & 0 & 2 \\
Intestinal tuberculosis & 0 & 1 & 1 \\
Meckel's diverticulum & 1 & 0 & 1 \\
Nonspecific inflammation & 1 & 0 & 1 \\
Postoperative adhesion & 1 & 0 & 1 \\
Malignant & 5 & 4 & 9 \\
Primary adenocarcinoma & 1 & 3 & 4 \\
Lymphoma & 1 & 1 & 2 \\
Leiomyosarcoma & 1 & 0 & 1 \\
GIST & 1 & 0 & 1 \\
Undifferentiated carcinoma & 1 & 0 & 1 \\
\hline Total & 19 & 7 & 26 \\
\hline
\end{tabular}

GIST, gastrointestinal stromal tumor. which is consistent with other findings $[18,19]$. The presence of weight loss may be associated with serious underlying pathology and should alert surgeons to suspect malignancy $[15,20]$.

Given its rare prevalence and confusing clinical picture, the diagnosis of adult intussusception is a true challenge and can be missed without imaging studies. Currently, abdominal CT scan is the most effective imaging tool to detect intussusception, with a diagnostic accuracy ranging from 58 to $100 \%$ [21, 22]. The typical image is formed by a thickened intestinal wall and mesentery within the lumen giving the pathognomonic "target sign" or "sausage-shaped" appearance according to the axial projection [23-25]. CT scan can identify the exact location of intussusception and reveal any threatening signs of intestinal nonviability. It can also recognize pathological lesions, helping to differentiate intussusception due to organic lesion (lead point intussusception) from intussusception without identified underlying lesion (nonlead point intussusception), which tends to be transient $[26,27]$. However, CT scan cannot always distinguish be- 
tween a pathological lesion and a thickened edematous intestinal wall except in cases of lipoma [25].

In the hands of experienced operators, ultrasound is a useful technique to detect intestinal invagination. The characteristic images include "target sign" or "doughnut sign" in the cross-section and "pseudo-kidney sign" in the longitudinal section $[28,29]$. However, interposition of air contained in distended loops and obesity can affect the image quality and the findings' accuracy. Consequently, we propose to achieve abdominal CT scan as a regular diagnostic test in all patients admitted for acute abdominal pain or intestinal obstruction.

Colonoscopy is reported to be useful in patients with subacute or chronic intestinal obstruction, especially in colonic forms. It helps to identify parietal lesions and to perform tissue biopsies. Nevertheless, it must be performed in selected patients given the high risk of perforation resulting from parietal ischemia and potentially necrosis [30, 31].

In our study, the preoperative diagnosis rate of intussusceptions was approximately $81 \%$. In the literature, this rate varies between 30 and 90\% [32-34]. Our relatively higher rate can be explained by the frequent use of CT scan in our country, particularly in recent years.

The exact mechanism of intussusception is still not well understood. However, most authors report that any lesion in the intestinal wall or intraluminal irritation can alter intestinal peristalsis and induce intestinal invagination $[22,35]$. Additionally, adult intussusception is due to an identifiable etiology in nearly $90 \%$ of cases $[2,14]$. In general, the majority of enteric intussusceptions are secondary to benign lesions. Malignant etiologies represent only $30 \%$ of lesions and include primary (mainly adenocarcinoma) or metastatic tumors $[16,36]$. Conversely, colonic intussusceptions are more likely due to malignant etiologies in up to $66 \%$ of cases $[23,33]$. In the present study, enteric intussusceptions were the most frequent type, in line with previous reports $[8,11]$. Malignant lesions were more frequently found in colonic intussusceptions than in enteric ones, and the most common malignancy was adenocarcinoma. Other authors reported similar results, confirming the high prevalence of malignant etiologies in colonic intussusceptions [7, 37].

Until now, there is no universally accepted approach to the optimal treatment of adult intussusceptions. Given the large proportion of underlying pathological lesions, surgical management continues to be the mainstay treatment modality for most patients. For colonic intussusceptions, reduction was avoided in our patients. En bloc resection without reduction is recommended by other researchers considering the high rate of malignancy [3840]. Furthermore, reduction exposes the patient to intraluminal seeding and venous dissemination of tumor cells, intestinal perforation during manipulation with possible spread of malignant cells into the peritoneal cavity, and increased risk of anastomotic complications in an edematous and inflamed bowel $[41,42]$.

As malignancy is less common in enteric intussusceptions, reduction can be performed before resection to reduce the extent of intestinal resection and to prevent short bowel syndrome. It is reported that probability of malignancy increases with age, past history of malignancy, and chronic history of Crohn's or celiac diseases [4345]. In our study, intraoperative reduction was adopted only for enteric intussusceptions in the absence of suspected signs of malignancy. However, 2 reduced intussusceptions have been shown to be secondary to malignant lesions. This situation must be considered during the surgical procedure because of the inability to distinguish benign from malignant lesions. Similarly, some authors recommended that enteric intussusceptions should also be resected without prior reduction $[9,38]$. However, reduction may be attempted only in young patients with strongly suggested benign lesions unless signs of ischemia or strangulation are detected $[41,46]$.

The expanded use of CT scan has increased the detection of asymptomatic and incidental intussusceptions in adults. These forms, more frequently without a detected pathological lead point, are secondary to transient peristaltic disorders and are likely to be resolved spontaneously. They are designated as idiopathic intussusceptions and usually affect the small bowel rather than the colon $[26,47]$. Confronted with this situation, the surgeon is confused about whether the patient must undergo surgical treatment or not. Many authors have recently suggested a more selective approach in the management of enteric intussusceptions. Shenoy [45] proposed that patients presenting with intestinal obstruction, digestive bleeding, abdominal palpable mass, or a pathological lesion on CT scan should undergo surgical treatment. Contrarily, Onkendi et al. [48] reported that enteric intussusceptions without a detectable lead point or obstructive symptoms are probably self-limiting and can be managed nonoperatively. Also, Lvoff et al. [49] and Mateen et al. [50] showed that enteric intussusceptions measuring $<3.5 \mathrm{~cm}$ in length do not require surgical exploration. However, if signs of intestinal obstruction or parietal ischemia appear during patient monitoring, a surgical exploration is necessary $[47,51]$. No idiopathic intussusception was detected in our study, and all cases were secondary to organic lesions. This may be explained by the fact that the data were collected only from the surgical records and CT scan was not systematically performed for abdominal complaints.

Laparoscopic surgery for adult intussusceptions is currently feasible and safe in experienced hands $[52,53]$. This approach, with both diagnostic and therapeutic possibilities, offers all the advantages of mini-invasive surgery. It is a useful adjunct to the conservative approach that allows 
exploring the abdominal cavity without subjecting the patient to aggressive incisions [51,54]. Within our institution, laparoscopic activities have increased since 2010 with a young and ambitious surgical team. We have successfully used this approach in 3 cases for segmental intestinal resection and in 1 case of right hemicolectomy with an uneventful postoperative course. Results of surgery in adult intussusceptions are generally good, but the long-term prognosis depends mainly on the underlying diseases [16, 20].

The major limitations of this study were its retrospective design and its small sample size due to the rarity of adult intussusceptions. Inclusion criteria related only to the patients' surgical records were another limitation. Thus, the incidence of this disease is certainly underestimated. A prospective multi-institutional study, involving a larger number of patients, seems to be necessary to draw relevant conclusions.

\section{Conclusion}

Adult intussusception is an infrequent pathology with a really challenging diagnosis that requires a high level of suspicion. It should be considered in any patient with subacute abdominal pain. However, the wide use of CT scan, the most effective imaging modality, makes diagnosis easier and more accurate. Adult intussusception is often due to an underlying lesion that requires surgical intervention. Given the high rate of associated malignancy, en bloc resection without attempting reduction should be the treatment of choice of colonic intussusceptions. A more selective approach is recommended for patients with enteric intussusceptions, especially in asymptomatic and incidental forms. Conservative management with close monitoring can be applied in selected patients.

\section{Acknowledgement}

The authors would like to thank the team of the Department of Visceral Surgery of Mohammed V Military Hospital for providing support and helping in preparing the manuscript.

\section{Statement of Ethics}

The study was performed in accordance with the Medical Ethics Committee's requirements. Given the retrospective design, written consent was not required.

\section{Disclosure Statement}

The authors have no conflicts of interest to declare.

\section{Funding Sources}

The authors did not receive any funding.

\section{Author Contributions}

M.T. participated in the conception and design of the study, performed the collection of data, and drafted the manuscript. A.A.A. contributed to the analysis and interpretation of data and revised the manuscript.

\section{References}

1 de Moulin D. Paul Barbette, M.D.: a seventeenth-century Amsterdam author of bestselling textbooks. Bull Hist Med. 1985;59(4): 506-14.

2 Marsicovetere P, Ivatury SJ, White B, Holubar SD. Intestinal Intussusception: Etiology, Diagnosis, and Treatment. Clin Colon Rectal Surg. 2017 Feb;30(1):30-9.

3 Azar T, Berger DL. Adult intussusception. Ann Surg. 1997 Aug;226(2):134-8.

4 Gomes A, Sousa M, Pignatelli N, Nunes V. Adult intussusception: a single-center 10year experience. Eur Surg. 2013 Jan;45(5): 239-44.

5 Traoré D, Sissoko F, Ongoïba N, Traoré I, Traoré AK, Koumaré AK. Adult intussusception: diagnostic pitfalls, morbidity and mortality in a developing country. J Visc Surg. 2012 Jun;149(3):e211-4.

6 Hong KD, Kim J, Ji W, Wexner SD. Adult intussusception: a systematic review and metaanalysis. Tech Coloproctol. 2019 Apr;23(4): 315-24.

7 Ongom PA, Opio CK, Kijjambu SC. Presentation, aetiology and treatment of adult intus- susception in a tertiary Sub-Saharan hospital: a 10-year retrospective study. BMC Gastroenterol. 2014 May;14(1):86.

8 Zubaidi A, Al-Saif F, Silverman R. Adult intussusception: a retrospective review. Dis Colon Rectum. 2006 Oct;49(10):1546-51.

9 Honjo H, Mike M, Kusanagi H, Kano N. Adult Intussusception: A Retrospective Review. World J Surg. 2015 Jan;39(1):134-8.

10 Kaval S, Singhal BM, Kumar S, Singh CP. Adult intussusception: an institutional experience and review of literature. Arch Int Surg. 2014;4(1):25-30.

11 Barussaud M, Regenet N, Briennon X, de Kerviler B, Pessaux P, Kohneh-Sharhi N, et al. Clinical spectrum and surgical approach of adult intussusceptions: a multicentric study. Int J Colorectal Dis. 2006 Dec;21(8):834-9.

12 Chang CC, Chen YY, Chen YF, Lin CN, Yen $\mathrm{HH}$, Lou HY. Adult intussusception in Asians: clinical presentations, diagnosis, and treatment. J Gastroenterol Hepatol. 2007 Nov;22(11):1767-71.

13 Lindor RA, Bellolio MF, Sadosty AT, Earnest F 4th, Cabrera D. Adult intussuscep- tion: presentation, management, and outcomes of 148 patients. J Emerg Med. 2012 Jul;43(1):1-6.

14 Ciftci F. Diagnosis and treatment of intestinal intussusception in adults: a rare experience for surgeons. Int J Clin Exp Med. 2015 Jun; 8(6):10001-5.

15 Potts J, Al Samaraee A, El-Hakeem A. Small bowel intussusception in adults. Ann R Coll Surg Engl. 2014 Jan;96(1):11-4.

16 Erkan N, Haciyanli M, Yildirim M, Sayhan H, Vardar E, Polat AF. Intussusception in adults: an unusual and challenging condition for surgeons. Int J Colorectal Dis. 2005 Sep;20(5): 452-6.

17 Martín-Lorenzo JG, Torralba-Martinez A, Lirón-Ruiz R, Flores-Pastor B, Miguel-Perelló J, Aguilar-Jimenez J, et al. Intestinal invagination in adults: preoperative diagnosis and management. Int J Colorectal Dis. 2004 Jan; 19(1):68-72.

18 Gupta RK, Agrawal CS, Yadav R, Bajracharya A, Sah PL. Intussusception in adults: institutional review. Int J Surg. 2011;9(1):915 . 
19 Gupta V, Doley RP, Subramanya Bharathy KG, Yadav TD, Joshi K, Kalra N, et al. Adult intussusception in Northern India. Int J Surg. 2011;9(4):297-301.

20 Tan KY, Tan SM, Tan AG, Chen CY, Chng HC, Hoe MN. Adult intussusception: experience in Singapore. ANZ J Surg. 2003 Dec; 73(12): 1044-7.

21 Gayer G, Zissin R, Apter S, Papa M, Hertz M. Pictorial review: adult intussusception-a CT diagnosis. Br J Radiol. 2002 Feb;75(890):18590.

22 Yakan S, Caliskan C, Makay O, Denecli AG, Korkut MA. Intussusception in adults: clinical characteristics, diagnosis and operative strategies. World J Gastroenterol. 2009 Apr; 15(16):1985-9.

23 Amr MA, Polites SF, Alzghari M, Onkendi EO, Grotz TE, Zielinski MD. Intussusception in adults and the role of evolving computed tomography technology. Am J Surg. 2015 Mar;209(3):580-3.

24 Bar-Ziv J, Solomon A. Computed tomography in adult intussusception. Gastrointest Radiol. 1991;16(3):264-6.

25 Park SB, Ha HK, Kim AY, Lee SS, Kim HJ, Park BJ, et al. The diagnostic role of abdominal CT imaging findings in adults intussusception: focused on the vascular compromise. Eur J Radiol. 2007 Jun;62(3):406-15.

$26 \mathrm{Kim}$ YH, Blake MA, Harisinghani MG, Archer-Arroyo K, Hahn PF, Pitman MB, et al. Adult intestinal intussusception: CT appearances and identification of a causative lead point. Radiographics. 2006 May-Jun;26(3): 733-44.

27 Tresoldi S, Kim YH, Blake MA, Harisinghani MG, Hahn PF, Baker SP, et al. Adult intestinal intussusception: can abdominal MDCT distinguish an intussusception caused by a lead point? Abdom Imaging. 2008 Sep-Oct;33(5): 582-8.

28 Boyle MJ, Arkell LJ, Williams JT. Ultrasonic diagnosis of adult intussusception. Am J Gastroenterol. 1993 Apr;88(4):617-8.

29 Cerro P, Magrini L, Porcari P, De Angelis O. Sonographic diagnosis of intussusceptions in adults. Abdom Imaging. 2000 Jan-Feb;25(1): 45-7.

30 Kim D, Jung H, Kim M, Lee J, Kim S, Kang D, et al. Endoscopic Treatment of Intussusception due to Intestinal Tuberculosis. Clin Endosc. 2017 Mar;50(2):206-8.
31 Wang N, Cui XY, Liu Y, Long J, Xu YH, Guo $\mathrm{RX}$, et al. Adult intussusception: a retrospective review of 41 cases. World J Gastroenterol. 2009 Jul;15(26):3303-8.

32 Eisen LK, Cunningham JD, Aufses AH Jr. Intussusception in adults: institutional review. J Am Coll Surg. 1999 Apr;188(4):390-5.

33 Ghaderi H, Jafarian A, Aminian A, Mirjafari Daryasari SA. Clinical presentations, diagnosis and treatment of adult intussusception, a 20 years survey. Int J Surg. 2010;8(4):318-20.

34 Ma KW, Li WH, Cheung MT. Adult intussusception: A 15-year retrospective review. Surg Pract. 2012 Feb;16(1):6-11.

35 Marinis A, Yiallourou A, Samanides L, Dafnios N, Anastasopoulos G, Vassiliou I, et al. Intussusception of the bowel in adults: a review. World J Gastroenterol. 2009 Jan;15(4): 407-11.

36 Hanan B, Diniz TR, da Luz MM, da Conceição SA, da Silva RG, Lacerda-Filho A. Intussusception in adults: a retrospective study. Colorectal Dis. 2010 Jun;12(6):574-8.

37 Begos DG, Sandor A, Modlin IM. The diagnosis and management of adult intussusception. Am J Surg. 1997 Feb;173(2):88-94.

38 Goh BK, Quah HM, Chow PK, Tan KY, Tay $\mathrm{KH}, \mathrm{Eu} \mathrm{KW}$, et al. Predictive factors of malignancy in adults with intussusception. World J Surg. 2006 Jul;30(7):1300-4.

39 Kim JW, Lee BH, Park SG, Kim BC, Lee S, Lee SJ. Factors predicting malignancy in adult intussusception: an experience in university-affiliated hospitals. Asian J Surg. 2018 Jan;41(1): 92-7.

40 Kim KH, Namgung H, Park DG. Adult intussusceptions: preoperative predictive factors for malignant lead point. Ann Surg Treat Res. 2014 May;86(5):244-8.

41 El-Sergany A, Darwish A, Mehta P, Mahmoud A. Community teaching hospital surgical experience with adult intussusception: study of nine cases and literature review. Int J Surg Case Rep. 2015;12:26-30.

42 Yamada H, Morita T, Fujita M, Miyasaka Y, Senmaru N, Oshikiri T. Adult intussusception due to enteric neoplasms. Dig Dis Sci. 2007 Mar;52(3):764-6.
43 Gonda TA, Khan SU, Cheng J, Lewis SK, Rubin M, Green PH. Association of intussusception and celiac disease in adults. Dig Dis Sci. 2010 Oct;55(10):2899-903.

44 Shah A, Roberts J, Lipsky H, Twersky Y, Hirth M, Chawla K. Enteroenteric intussusception: an unusual presentation of Crohn's disease in an adult patient. Am J Gastroenterol. 1995 Dec;90(12):2231-2

45 Shenoy S. Adult intussusception: A case series and review. World J Gastrointest Endosc. 2017 May;9(5):220-7.

46 Wang LT, Wu CC, Yu JC, Hsiao CW, Hsu CC, Jao SW. Clinical entity and treatment strategies for adult intussusceptions: 20 years' experience. Dis Colon Rectum. 2007 Nov;50(11): 1941-9.

47 Aydin N, Roth A, Misra S. Surgical versus conservative management of adult intussusception: case series and review. Int J Surg Case Rep. 2016;20:142-6.

48 Onkendi EO, Grotz TE, Murray JA, Donohue $\mathrm{JH}$. Adult intussusception in the last 25 years of modern imaging: is surgery still indicated? J Gastrointest Surg. 2011 Oct;15(10):1699705 .

49 Lvoff N, Breiman RS, Coakley FV, Lu Y, Warren RS. Distinguishing features of self-limiting adult small-bowel intussusception identified at CT. Radiology. 2003 Apr;227(1):6872.

50 Mateen MA, Saleem S, Rao PC, Gangadhar V Reddy DN. Transient small bowel intussusceptions: ultrasound findings and clinical significance. Abdom Imaging. 2006 Jul-Aug; 31(4):410-6.

51 Varban OA, Ardestani A, Azagury DE, Kis B, Brooks DC, Tavakkoli A. Contemporary management of adult intussusception: who needs a resection? World J Surg. 2013 Aug; 37(8):1872-7.

52 Greenley CT, Ahmed B, Friedman L, Deitte L Awad ZT. Laparoscopic management of sigmoidorectal intussusception. JSLS. 2010 JanMar;14(1):137-9.

53 McKay R. Ileocecal intussusception in an adult: the laparoscopic approach. JSLS. 2006 Apr-Jun;10(2):250-3.

54 Sundaram B, Miller CN, Cohan RH, Schipper MJ, Francis IR. Can CT features be used to diagnose surgical adult bowel intussusceptions? AJR Am J Roentgenol. 2009 Aug; 193(2):471-8. 